\title{
Algal Biodiesel-Promising Source to Power Diesel Engines
}

\author{
Authors \\ Ajay Gupta ${ }^{1}$, C.Srinidhi ${ }^{2}$ \\ ${ }^{1}$ U.G. Student, Mechanical Engineering Department, SRTTC, Khamshet, Pune-410405 \\ ${ }^{2}$ Asst. professor, Mechanical Department, SRTTC, Khamshet, Pune-410405 \\ Email: ajaygpt303@gmail.com
}

\begin{abstract}
The need of fuel is increasing constantly due to increase in population and industrialization all over the world. The increase in population and industrialization has put the increasing pressure on the use of nonrenewable resources. The non-renewable resources like petrol, diesel, coal, natural gas, etc. are used for production of energy. The availability of fossil fuel is continuously decreasing due to increase in demand continuously, these reasons makes the researchers to find new renewable alternative fuel like biofuels. There are various vegetable plants like karanja, neem, soyabean, etc. are used for producting biodiesel only problem is the land availability, so the algae is now been used to produce biodiesel. It has been reported that use of biodiesel reduce the emission and increases the performance of engine. In this review we present an overview about algae use for biodiesel production, including their cultivation, harvesting and processing.
\end{abstract}

Key Words: Fossil fuel, Algae, Biodiesel.

\section{INTRODUCTION}

With the rapid increase in population, industrialization there is a increasing demand for energy, due to which there is rapid decrease in fossil fuel reserves and increasing concerns about global warming which lead to the development of renewable resources like biofuels. In the last 10 years, many studies have been conducted on biofuels for substituting fossil fuels and reduce the greenhouse gas (GHG) emission which is responsible for global warming ${ }^{[2]}$. Biofuel can be classified into three generations as first generation, second generation and third generation according to different parameters. Figure 1 depicts the generations of biofuels;

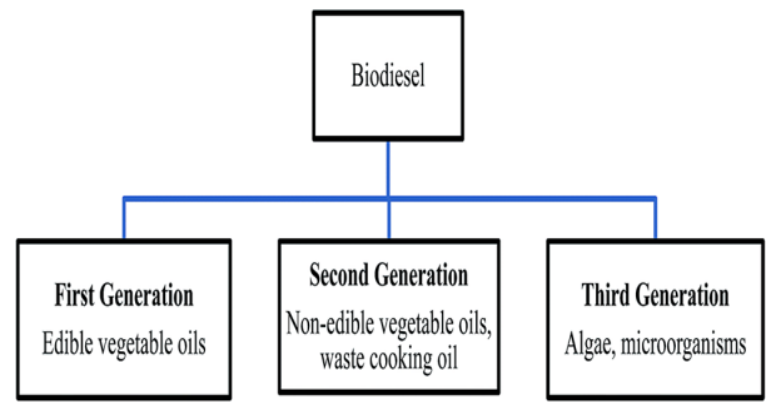

Figure 1: Generations of biofuels.
There will be certain limitations in the use of these vegetable oils as alternate fuels because of its food demand, life span, lower yield/ ha, higher land usage and higher price ${ }^{[3]}$. Hence the algae are good option for production of biodiesel as it has higher biomass yields per day and per unit cropping area. The use of raw algal oil can overcome problems related with the use of expensive chemicals and procedures during the transesterification reaction necessary to produce Bio-Diesel ${ }^{[4]}$. The aim of this study was to evaluate the potential of algae biodiesel to replace diesel in future.

\section{ALL ABOUT ALGAE.}

Algae are a diverse group of aquatic organisms that have the ability to conduct photosynthesis. The term "algae" covers many different organisms capable of producing oxygen through photosynthesis. Photosynthesis is the process of harvesting light energy from sun to convert it it into carbohydrates. Algae do not have true roots, stems, leaves, vascular tissue and have simple reproductive structure. The algae 
can be classified into two types' microalgae and macroalgae. The unicellular forms are known as microalgae where as the multicellular forms comprise macroalgae. Microalgae consists a vast group of photosynthetic, heterotrophic organisms which have a great potential for cultivation as energy crops. Microalgae are divided into two prokaryotic divisions (Cyanophyta and Prochlorophyta) and nine eukaryotic divisions (Glaucophyta, Rhodophyta, Heterokontophyta, Haptophyta, Cryptophyta, Dinophyta, Euglenophyta, Chlorarachniophyta and Chloropha) ${ }^{[6]}$.

Algae as a feedstock for biodiesel are in the preliminary stages of research but have shown immense potential to provide alternative and a new generation feedstock ${ }^{[5]}$. Like plants, algae require three main components togrow: sunlight, carbondioxide and water. Photosynthesis is an important bio-chemical process in which plants, algae, with some bacteria convert the energy of sunlight to chemical energy ${ }^{[1]}$. Main characteristics of algae are:-

a. High biomass yield per unit of light and area.

b. It have a high oil or starch content

c. Do not require agricultural land

d. It is a renewable source of energy.

e. Can grow in any type of water resources fresh water is not essential.

f. It is eco-friendly.

g. Algae act as cleaning agent.

From the recent research into using algae for production of biodiesel they have potential to become future source of energy and to replace nonrenewable resources.

\section{STEPS FOR CONVERSION ALGAE INTO BIODIESEL.}

There are four main steps for conversion of algae into biodiesel and they are:-
a. Algae cultivation.
b. Algae harvesting.
c. Oil extraction from algae.
d. Oil to the biodiesel conversion through various processes.

\subsection{Algae cultivation.}

Like plants, algae use the sunlight for the process of photosynthesis. Photosynthesis is an important biochemical process in which plants; algae convert the energy of sunlight to chemical energy. Algae capture light energy through photosynthesis and convert inorganic substances into simple sugars that is the carbohydrates using the captured energy. The cultivation is basically done in two ways.

1. Ponds.

a. Cultivation of algae in open ponds.

b. Cultivation of algae in closed ponds.

2. Photobioreactors.

\subsubsection{Cultivation of algae in open ponds.}

Open ponds can be categorized into natural waters (lakes, lagoons, ponds) and artificial ponds or containers. The most commonly used systems include shallow big ponds, tanks, circular ponds and raceway ponds. In This system algae grow in their natural environment. The raceways are typical lymade from poured concrete, or they are simply dug into the earth and lined with a plastic liner. These raceways vary from a few feet in length to thousands of meters ${ }^{[7]}$. One of the major advantages of open ponds is that they are easier to construct, operate and low production and operating cost than most closed systems. However, major limitations in open ponds include poor light utilization by the cells, evaporative losses, diffusion of $\mathrm{CO} 2$ to the atmosphere, and requirement of large areas of land. The environment in and around the pond is not completely under control. Figure 2 shows the open pond algae cultivation.

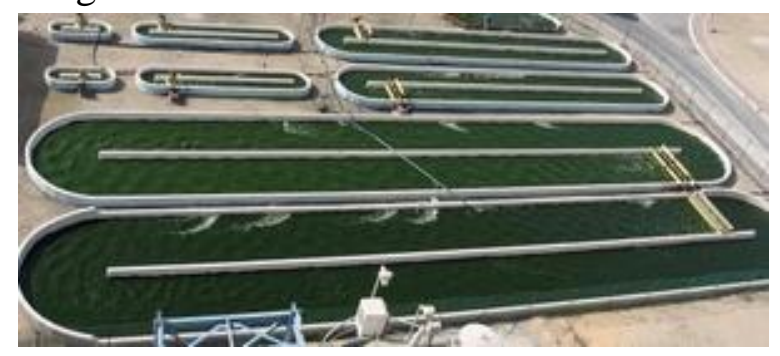

Figure 2: Open pond algae cultivation.

\subsubsection{Cultivation of algae in closed ponds.}

An alternative to open ponds are closed ponds where the control over the environment is much better than that for the open ponds. As a variation of 
the open pond system, the idea behind the closed pond is to close it off, to cover a pond or pool with a greenhouse. It takes care of many of the problems associated with an open system. It allows more species to be grow in the pond, it allows the species that are being grown to stay dominant, and it extends the growing season, only slightly if unheated, and if heated it can produce year round. The construction and operation of closed pond is more expensive then open pond cultivation but it result into more algae cultivation due to controlled environment.

\subsubsection{Photo bioreactors.}

A photo bioreactor is closed equipment which provides a controlled environment and enables high productivity of algae. Photo bioreactors (PBRs) regulates and control nearly all the biotechnologically important parameters such as no $\mathrm{CO}_{2}$ losses, reduce the risk of contamination of unwanted algae, reproducible cultivation conditions, controllable hydrodynamics and temperature ${ }^{[8]}$. However, it should be noted that although photo bioreactors significantly reduce the growth of competitive algal weeds, they cannot completely eliminate the growth of contaminants ${ }^{[9]}$. Figure 3 shows the photo bioreactors.

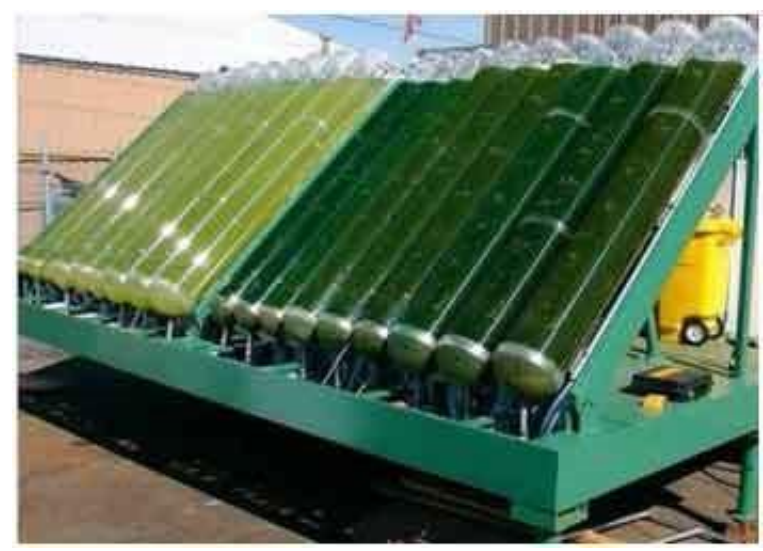

Figure 3: Photo bioreactors.

\section{ALGAE HARVESTING.}

Gathering algae consists of separating algae from the growing medium, drying, and processing it to obtain the desired product. Separating algae from its medium is known as harvesting. Biomass harvesting is the one of the most contaminating process in the Production of algae-based biofuels. At this stage, algae biomass from the preceding cultivation system typically carries high water content and, in most cases, which is not suiteable for conversion to biofuel products until it has undergone some degree of dewatering and drying ${ }^{[10]}$. Harvesting and dewatering processes can be divided into two categories, they are:-

a. Those in which the dewatering is performed directly on the algae culture, and ${ }^{[11]}$.

b. Those involving collection of the algae into macroscopic masses to facilitate the dewatering process ${ }^{[11]}$.

Macroalgae harvesting employs manpower whereas, microalgae can be harvested using the various processes such as microscreens, centrifugation, and flocculation or by froth flotation.

\section{OIL EXTRACTION FROM ALGAE.}

After the harvesting of algae the oil is been extracted through the various process, which are classified into two types of methods as:-

1. Mechanical methods.

The mechanical methods are further classified as:-

1. Expeller press.

2. Ultrasonic-assisted extraction.

2. Chemical methods

The chemical methods are further classified as:-

1. Hexane solvent method.

2. Soxhlet extraction.

3. Supercritical fluid extraction.

\subsubsection{Expeller press.}

In this method algae is been dried but it retain it's oil contain and then it is press in the oil press for the extraction of oil. Expeller press process cannot remove every last trace of oil from the algae even after the expeller press process significant amount of the oil remain trapped into the algae. Many of the commercial manufacturers of vegetable oil use a combination of mechanical pressing and chemical solvents in extracting oil.

\subsubsection{Ultrasonic-assisted extraction.}

In this method oil is been extracted with the help of ultrasonic wave which is been created by the ultrasonic reactors. The ether is added into the dried algae and then ultra-sonic wave is provided for 30 
minutes, (ultrasonic waves are used to create cavitation bubbles in a solvent material) due to Ultra-sonic the cell wall rapture of algae takes place. Filter it with sieves, manually press algae to extract algal oil, algal oil has use to further transesterification process ${ }^{[12]}$.

\subsubsection{Hexane solvent method.}

The hexane solvent extraction method can be used alone or it can be used along with expeller press method. The pulp of the algae after the extraction of oil from expeller press is mixed with the cyclohexane so that the remaining oil from the pulp is dissolved into the cyclo-hexane the pulp is filtered out from it. Oil from the cyclo-hexane is been separated with the help of distillation process. Distillation is the process of separating the component or the substance with the help of selective evaporation and condensation.

\subsubsection{Soxhlet extraction.}

In the soxhlet extraction method various chemical solvents are use for the the extraction of oil like hexane and petroleum ether. The dried algae are placed in algae reservoir and then hexane is added. The algae is completely immersed into the hexane and small amount of it is dissolved into hexane. The hexane is boiled due to which the hexane is vaporize and as the oil has higher boiling point it does not vaporize in this way oil is been extracted by soxhlet extraction process ${ }^{[13]}$.

\subsubsection{Supercritical fluid extraction.}

The supercritical fluid extraction is the process of separating the one component from the other with the help of supercritical fluid. Carbon dioxide is the most used supercritical fluid some time it is modified with the help of ethanol and methanol. This solvent has some advantages including nontoxity; non explosive, non flammability, low cost, availability and ease of being removed from extract oils ${ }^{[14]}$. The basic principle of supercritical fluid extraction is that when the feed material comes in the contact with the supercritical fluid the volatile substances will partition into the supercritical phase. After the soluable material is dissolved the supercritical fluid is been removed from the feed material. The supercritical fluid is been separated with help of pressure and temperature change.

\section{TRANSESTERIFICATION.}

Transesterification is the process through which the algae oil must go through to become biodiesel. Transesterification, also called alcoholysis, is the displacement of alcohol from an ester by another alcohol in a process similar to hydrolysis, except that an alcohol is employed instead of water. Suitable alcohols used in transesterification process are methanol, ethanol, propanol, butanol and amyl alcohol ${ }^{[15]}$. The transesterification of algae oil is mostly done by ethanol and sodium ethanolate which serve as a catalyst. The ethanol reacts with the algal oil ( the triglyceride) in the presence of catalyst to produce biodiesel and glycerol.

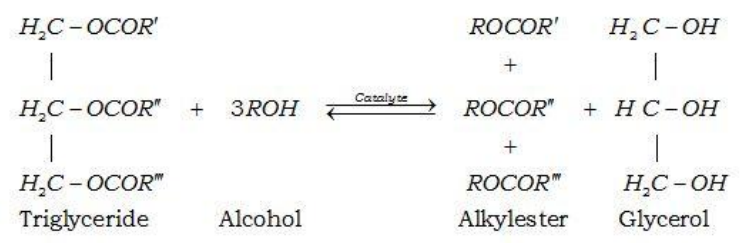

Figure 4: General equation of transesterification.

\section{CONCLUSION AND FUTURE SCOPE.}

Recently, it is challenging to find the different alternative for the fossil fuels. Due to presence of various adavantages of algal biofuels low land requirement and high productivity it has been considered as best resource to replace the fossil fuels. Algal biofuel has potential to reduce the impact of release of $\mathrm{CO}_{2}$ from the fossil fuel. With locally produced biofuels, many countries have reduced their dependance on fossil fuels. It may not solve all problems in one blow but a nation can save billions by reducing their usage on foreign oil. the Bio-Diesel is capable of bringing revolution in future by replaceing the various non-renewable resources.

\section{REFERENCES}

1. Alpesh Mehta, Dr.Nirvesh Mehta (2015), Algae Biofuel: Futuristic Trends in Fuel Industry, International Research Journal of Engineering and Technology. 
2. A. Muthukumar, S. Elayaraja, T. T. Ajith kumar, S. Kumaresan and T. Balasubramanian (2012), Biodiesel production from marine microalgae Chlorella marina and Nannochloropsis salina, Journal of Petroleum Technology and Alternative Fuels

3. Vandna Pathak, Ravindra Singh, Pankaj Gautam(2015), Algal oil production: Research Paper, Research Journal of Chemical and Environmental Sciences.

4. Karande Sheetal R., Wagh Mahesh M.(2015), Bio-Diesel From Algae "Empowering The World of Energy: A Review", International Research Journal of Engineering and Technology.

5. Pathak Vandna, Singh Ravindra, Gautam Pankaj and Pandey Rakesh kumar(2015), Microalgae as Emerging source of Energy: A Review, Research Journal of Chemical Sciences.

6. T. Mutanda, D. Ramesh, S. Karthikeyan, S. Kumari, A. Anandraj, F. Bux(2011), Bioprospecting for hyper-lipid producing microalgal strains for sustainable biofuel production, Bioresource Technology.

7. Martin Gross (2013), Development and optimization of algal cultivation systems, Graduate Theses and Dissertations. Paper 13138.

8. Giuliano Dragone, Bruno Fernandes, António A. Vicente, and José A. Teixeira, Third generation biofuels from microalgae.

9. Worasaung Klinthong, Yi-Hung Yang, Chih-Hung Huang, Chung-Sung Tan(2015), A Review: Microalgae and Their Applications in $\mathrm{CO} 2$ Capture and Renewable Energy, Aerosol and Air Quality Research.

10. Jigar H Shah, Abhijeet Deokar, Kushal Patel, Keyur Panchal, Alpesh V. Mehta, A Comprehensive Overview on Various Method of Harvesting Microalgae According to Indian Perspective, International Conference on Multidisciplinary Research \& Practice.
11. Manjinder Singh, Rekha Shukla, and Keshav Das, Harvesting of Microalgal Biomass, Biorefining and Carbon Cycling Program.

12. Gulab Chand Shah, Alkesh Patidar, Vikash Urkude, Anil Hurmale, Sudheeer Choudhary, Mahavir Yadav and Archana Tiwari, Analysis and Characterization of Algal Oil by Using Different Chromatographic Techniques for the Higher Production of Biodiesel from Scenedesmus Dimorphus Algal Species, Open Access Scientific Reports.

13. Ben Browne, Ryan Gibbs, Jackson McLeod, Michael Parker, Wade Schwanda, Kyle Warren (2010), Oil Extraction from Microalgae.

14. Soroush Zarinabadi, Riyaz Kharrat, Ali Vaziri Yazdi(2010), Extraction of Oil from Canola Seeds With Supercritical Carbon Dioxide: Experimental and Modeling, Proceedings of the World Congress on Engineering and Computer Science 2010 Vol II.

15. S.Siva, C.Marimuthu(2015), Production of Biodiesel by Transesterification ofAlgae Oil with an assistance of Nano-CaO Catalyst derived from Egg Shell, International Journal of ChemTech Research.

16. Shuvashish Behera, Richa Singh, Richa Arora, Nilesh Kumar Sharma, Madhulika Shukla and Sachin Kumar(2014), Scope of Algae as Third Generation Biofuels,. 